\title{
FUERA DE CAMPO. TRAYECTORIAS E IDENTIDADES DE INVESTIGADORES LATINOAMERICANOS HOY
}

Out of the Field. Biographical Paths and Identities of Latin American

Researchers Today

\author{
Gabriel Gatti*; Ignacio Irazuzta**; Danilo Martuccelli*** \\ * Centro de Estudios sobre la Identidad Colectiva, Universidad del País Vasco/Euskal \\ Herriko Unibertsitatea; ${ }^{* *}$ Tecnológico Monterrey; ${ }^{* * *}$ Université Paris Descartes, USPC, \\ miembro del IUF, Cerlis-CNRS \\ g.gatti@ehu.eus; Ignacio.irazuzta@itesm.mx; danilomartuccelli@gmail.com
}

Gatti, G., Irazuzta, I., Martuccelli, D., 2015, "Fuera de campo. Trayectorias e identidades de investigadores latinoamericanos hoy", en Papeles del CEIC, vol. 2015/1, CEIC (Centro de Estudios sobre la Identidad Colectiva), Universidad del País Vasco, http://dx.doi.org/10.1387/pceic.13886

“Palabras como 'intelectual' y 'latinoamericano' me hacen levantar instintivamente la guardia, y si además aparecen juntas me suenan enseguida a disertación del tipo de las que terminan casi siempre encuadernadas (iba a decir enterradas) en pasta española. Súmale a eso que llevo dieciséis años fuera de Latinoamérica, y que me considero sobre todo como un cronopio que escribe cuentos y novelas sin otro fin que el perseguido ardorosamente por todos los cronopios, es decir su regocijo personal" (Julio Cortazar, 1967, "Situación del intelectual latinoamericano", carta a Roberto Fernández Retamar)

Este número de Papeles del CEIC propone lo que muchos considerarán un extraño ejercicio de reflexividad a medio camino entre quehacer académico e introspección biográfica. Por ello, sin duda, los lectores tendrán interpretaciones muy disímiles a propósito de los textossemblanzas que leerán. Estas lecturas serán tanto más distintas entre sí en cuanto los autores recopilados no representan bajo ningún aspecto un movimiento intelectual homogéneo, y que más allá de ciertas coincidencias generacionales no son, en absoluto, miembros de lo que podría denominarse una "generación" intelectual. Dicho brevemente: 
estamos ante una miscelánea heterogénea de itinerarios y proyectos intelectuales que es preciso leer en este sentido.

Sin embargo, detrás de esta diversidad de reflexiones, una temática común enhebra todos los artículos reunidos. Todos y cada uno de los autores recopilados han propuesto una lectura, desde sus itinerarios personales y profesionales de lo que a sus ojos constituye las principales condiciones o razones sociales de la producción de sus miradas sociológicas sobre América Latina. En este esfuerzo, algunos han subrayado experiencias biográficas, viajes, estadías o exilios; otros han considerado lecturas y encuentros; los hay, también, que prefirieron descentrar la reflexión hacia sus universos profesionales y los que interrogaron la diversidad de las culturas nacionales en las que trabajan; y todos, realmente, propusieron una interpretación, desde ellos mismos y su labor profesional, de la época actual. A través pues de una miscelánea de experiencias, el objetivo central de este número es proponer un panorama, no exhaustivo, pero esperamos significativo por los perfiles reunidos, del quehacer actual de científicos sociales que trabajan sobre América Latina, desde muy distintos contextos nacionales y situaciones profesionales.

Para aprehender esta realidad, los artículos, incluso si la respuesta a la solicitud de los coordinadores del número haya sido muy diversa en sus apropiaciones personales, se organizan inicialmente desde un itinerario vital y profesional desde el cual se leen, hacia el pasado o el presente, temáticas o problemas del trabajo sociológico contemporáneo. La diversidad de tonos y de preocupaciones es evidente, y sin embargo, detrás de esta manifiesta heterogeneidad es legítimo notar una experiencia común. Todos los artículos, más allá de sus singularidades, dan cuenta de la consolidación de nuevos perfiles de investigadores sociales cuya emergencia indica la aparición de un nuevo momento institucional e histórico en el desarrollo de las ciencias sociales sobre América Latina.

Pensemos brevemente en ese momento, que es nuevo respecto a un viejo imaginario, el del intelectual latinoamericano, frente o con el cual estos textos se posicionan. Desde la fundación, América Latina fue imaginada siempre como un magnífico contenedor vacío a la espera de desarrollar en ella sueños pergeñados en mapas que le eran previos. Militares, religiosos, geólogos o botánicos, legisladores o intérpretes, coincidieron en eso, y jugaron bien ese rol. Es cosa vieja, que abarca desde las ya lejanas fundaciones de las muy viejas Ciudades Letradas y de los contemporáneos procesos constituyentes y llega con vigor a la generación - también ya 
propia de la historia contada- de los que vivieron sus muchos procesos reconstituyentes, ya en Siglo XX. Una figura recorre esa larga historia, y sin cambiarse demasiado el traje: el intelectual latinoamericano. Crítico, liberal, socialista o libertario, orgánico o consejero, tradicionalista o internacionalista, desde casa o desde el exilio, Chicago Boy o su contrario, atraviesa la historia del continente. No parece difícil por eso pensar que hoy existe no ya solo un personaje social (precisamente el del intelectual latinoamericano) sino también un campo intelectual latinoamericano, escena donde ejecuta su papel. Ficticio o real, la del "intelectual latinoamericano" es una figura imaginable.

Y sin embargo... Mucho ha llovido desde Sarmiento, es claro, pero tampoco es poco el tiempo pasado desde Angel Rama, José Joaquín Brunner, Nestor García Canclini, Vargas Llosa o Renato Ortiz. Algunos de los herederos de esa tradición siguen activos y eficientes, con nombres y apellidos, con grandes nombres y apellidos; pero tienen que convivir hoy en ese campo con formas nuevas de entender el personaje, más extendidas, quizás incluso más democratizadas, probablemente menos glamorosas, entre otras cosas porque están más sujetas a pruebas, índices de impacto y gestiones vitales hechas a fuerza de currícula. Son las formas propias de una generación que, la de los firmantes de este texto introductorio, que si no es intelectual si tiene trazos biográficos comunes:

1) En el origen histórico, algunas declaraciones y acontecimientos de ruptura ("fin de la historia", cambios de régimen) y de apertura (apertura económica y política, globalización y transnacionalización de la vida social...). Provisto de nuevos medios de comunicación, el universo social de quienes habitan estos nuevos tiempos se va construyendo sobre el imperativo de la conectividad y las redes que, a la vez que otorgan forma y sustancia al hacer académico e intelectual, modifica también los imaginarios sobre el mundo y el tránsito en él.

2) En la trayectoria biográfica-académica, una variada muestra de historias: formados aqui y/o allá, con trabajo desarrollado sobre aquí y sobre allá, que se mueven de allí para acá y de acá para allí, que lo hicieron por razones muy distintas (desde el exilio o la emigración sin impulso político a la beca pre o postdoctoral), y que lo siguen haciendo por motivos variados (familias, comparaciones, nostalgias, objetos de estudio...), pero que lo hacen, tejiendo una red que liga su destino (Europa, en general, en menor medida Estados Unidos) con 
su origen (América), origen al que a veces vuelven sin dejar por eso de tener - de varios modos- un pie alli donde estuvieron.

3) En el presente institucional, una población de sujetos objeto de recurrentes intentos para comprenderla y objetivarla como diáspora, es decir, para dotarla de sentido y colocarla en sus panoramas nacionales. Algunos de esos intentos pueden provenir de las agencias científicas de sus naciones de origen, que interpelan a "sus" sujetos dispersos a través de diversos programas (Raíces, Conicet, Argentina; Red de Talentos, Conacyt, México; Científicos y tecnólogos Uruguayos en el Exterior, ANII, Uruguay) que reconocen esas trayectorias desplazadas y les proponen dobles inserciones. Otros sentidos provienen de sus representaciones sobre el lugar de origen -América Latina-, que pueden dar forma y contenido a sus objetos de estudio e, incluso, sostener proyectos asociativos de carácter académico (LASA). Otros, finalmente, pueden provenir de propuestas como esta, que presume que ha de haber sentido entre las circunstancias generaciones del desplazamiento.

Con todo y con eso, el grupo de autores de este número de Papeles del CEIC comparte rasgos transversales bien visibles. En primer lugar, y en continuidad con las generaciones precedentes, la mayor parte de los autores del presente número han efectuado estudios doctorales -o largas estadías de investigación- en los denominados paises del Norte (principalmente Estados Unidos y Europa). Sobre todo, en todos los textos presentados, más allá de movilidades geográficas y profesionales reales, la descentración bibliográfica sigue siendo una experiencia altamente compartida. Un proceso que va a la par, a medida que las formaciones de master y de doctorado se internacionalizan, con un incremento significativo de la circulación profesional dentro de la misma América Latina. Sin embargo, amén de esta última inflexión, la continuidad aparente observable en las referencias y autores con los que se discute, no debe llevar a desconocer una novedad mayor: a través de itinerarios personales muy distintos, lo que se observa es no solamente un proceso de transformación de la comunicación ente investigadores sino también la aparición de contactos profesionales de un nuevo tipo entre la sociología sobre América Latina y la producción científica europea y estadounidense.

En segundo lugar, los itinerarios presentados reflejan la importante transformación institucional observable en las condiciones del trabajo sociológico y la consolidación de una "carrera" de investigador que ha ido 
aparejada con la estandarización de los criterios de producción y evaluación. Por doquier se imponen en la producción científica exigencias de evaluación estandarizadas, mayores exigencias de productividad y de "calidad", y, progresivamente, incluso más allá del lugar de trabajo en donde se ejerce, la producción tiende incluso a ser promovida, a las jerarquías de las publicaciones, en inglés. Pero, y es un tema presente en varios artículos, si estas exigencias de profesionalidad crean en el momento actual un universo de producción en donde la mirada de los pares define y orienta cada vez más los estándares de calidad de la propia producción, esto no implica, en absoluto, la experiencia de trabajar en un "campo" intelectual bien delimitado. Por el contrario, si nos ceñimos a las experiencias reunidas, lo que prima entre muchos investigadores sociales hoy es un conjunto dispar y altamente idiosincrático de situaciones y experiencias de "nomadismo" intelectual y académico para unos, de "extranjeridad" cultural y existencial para otros.

Por último, y aún a riesgo de cristalizar el perfil de un "grupo" desde lo que no es sino, sin duda, un conjunto de trayectorias disímiles, es posible observar el afianzamiento, a través de temáticas muy disímiles entre sí, de una similar preocupación por dar con una lectura ampliada de la vida social. Más allá de las categorías empleadas e incluso de problemáticas transversales evocadas en los diferentes textos, lo que se afirma es una voluntad de abordar problemas sociales independientemente de la sola referencia a la sociología política. No es algo menor. Durante muchas décadas, la sociología política fue el área dominante de las ciencias sociales latinoamericanas. Para muchos, incluso, esta asociación era la mejor prueba que la sociología abordaba temas relevantes. La norecepción durante lustros de las microsociologías de la vida cotidiana en la región es una prueba, no anecdótica, de esta postura. Exista o no un vínculo con sus trayectorias, es manifiesto que la valorización de la diversidad temática refleja la toma de conciencia de que la sociología en la región debe incursionar en otras áreas de la vida social, más cotidianas, estudiar otros actores que los que fueron habitualmente considerados como legítimos, y hacerlo desde perspectivas menos totalizantes y políticas. Por supuesto, los "grandes" temas de la sociología están presentes y hay referencia a ellos en más de uno de los artículos reunidos, pero incluso en estos casos se observa el anhelo de abordarlos desde miradas descentradas y parciales. No que la política no esté presente. Por el contrario, la política como temática sociológica, como pasión intelectual 
o como factor de itinerario biográfico está constantemente y diversamente presente entre los autores reunidos, pero en todos ellos, al mismo tiempo, es manifiesta una innegable libertad de mirada con respecto a los imperativos explícitos de la política.

Sea como sea, el objetivo principal de estas líneas y de este número es llamar la atención sobre lo que es posible caracterizar como un momento particular en la producción de la sociología sobre América Latina: uno en el cual, en buena medida a causa de la aparición de nuevos perfiles profesionales, de la jerarquización de las carreras y de los centros de investigación, de la pluralización biográfica e institucional de las experiencias laborales en el Norte y en parte gracias al creciente diálogo Sur-Sur, la producción sociológica toma nuevos derroteros. En este sentido, esperamos que este número de Papeles del CEIC ayude no solo estimulando ejercicios similares en otros colegas o revistas, sino que también sirva de marco de reflexión colectiva para una perspectiva renovada de lo que fue otrora la sociología de los intelectuales. Una manera de pensar desde un conjunto de testimonios profesionales y personales el nuevo momento histórico de producción de la sociología sobre América Latina.

En esta suerte de prosopografía descentrada de América Latina, la disposición de los trabajo en el conjunto de este volumen se deja guiar por dos criterios evidentes. Ambos son, si no de posiciones - concepto teóricamente comprometido con una idea de campo que entendemos empíricamente rebasada por la propia situación de descentramiento que produce la migración en las trayectorias quienes participamos de este número de Papeles del CEIC - sí de lugares. En las primeras dos partes del volumen, el lugar se deja preñar de sentido geográfico. Reúnen éstas así aquellos trabajos que sitúan a los autores en diferentes puntos de la geografía descentrada de la investigación social que hacen sobre América Latina y en las reflexiones sobre la construcción y reconstrucción de sus identidades desde estas locaciones inestables y mestizas. En primera instancia aparecen tres artículos que ven a la región desde el desempeño profesional de sus autores en Europa: Danilo Martuccelli, Gabriel Gatti y Denis Merklen. Después, el lugar es a la vez ensimismado y dislocado. Ignacio Irazuzta y Kathya Araujo relatan sus experiencias desde los destinos de sus respectivos y diferentes desplazamientos dentro de América Latina. Finalmente, en los artículos de la tercera parte, sin dejar de hacerlo desde estas improntas de lugar, los autores - Pablo Francescutti, 
Felipe Arocena y Alejandro Castillejo- "objetivan su trabajo objetivante" inclinando con mayor énfasis sus escritos hacia el estilo autobiográfico, bien para describir prácticas académicas locales desde el posicionamiento extraño, bien encarnando con renovados trazos el perfil clásico del intelectual "liberador" de América Latina. 